\title{
The effect of concentration ratio and type of functional group on synthesis of CNT-ZnO hybrid nanomaterial by an in situ sol- gel process
}

\author{
Sekineh Hosseini Largani ${ }^{1}$ Mohammad Akbarzadeh Pasha ${ }^{1,2}$
}

Received: 16 November 2016/ Accepted: 11 December 2016/Published online: 23 December 2016

(C) The Author(s) 2016. This article is published with open access at Springerlink.com

\begin{abstract}
In this research, MWCNT-ZnO hybrid nanomaterials were synthesized by a simple sol-gel process using $\mathrm{Zn}\left(\mathrm{CH}_{3} \mathrm{COO}\right)_{2} \cdot 2 \mathrm{H}_{2} \mathrm{O}$ and functionalized MWCNT with carboxyl $(\mathrm{COOH})$ and hydroxyl $(\mathrm{OH})$ groups. Three different mass ratios of MWCNT:ZnO = 3:1, 1:1 and 1:3 were examined. The prepared nanomaterials were characterized by field emission scanning electron microscopy (FESEM), transmission electron microscopy (TEM), X-ray diffraction (XRD), energy dispersive X-ray spectroscopy (EDX) and Fourier transform infrared spectroscopy (FTIR). Successful growth of MWCNT-ZnO hybrids for both $\mathrm{COOH}$ and $\mathrm{OH}$ functional groups and all the three mass ratios were obtained. The $\mathrm{ZnO}$ nanoparticles attached on the surfaces of CNTs have rather spherical shapes and hexagonal crystal structure. By increasing the concentration of $\mathrm{ZnO}$, the number and average size of $\mathrm{ZnO}$ nanoparticles decorated the body of CNTs in hybrid structures increase. By increasing the $\mathrm{ZnO}$ precursor, the distribution of $\mathrm{ZnO}$ nanoparticles that appeared on the surface of CNTs becomes more uniform. The SEM observation beside EDX analysis revealed that at the same concentration ratio the amount of $\mathrm{ZnO}$ loading on the surface of MWCNT-COOH is more than MWCNT-OH. Moreover, the average size of $\mathrm{ZnO}$ nanoparticles attached on the surface of $\mathrm{COOH}$ functionalized CNTs is relatively smaller than that of $\mathrm{OH}$ functionalized ones.
\end{abstract}

Mohammad Akbarzadeh Pasha

m.akbarzadeh@umz.ac.ir

1 Department of Solid State Physics, Faculty of Basic Science, University of Mazandaran, 47416-95447 Babolsar, Iran

2 Research Laboratory of Carbon-based Nanostructures, Faculty of Basic Science, University of Mazandaran, Babolsar, Iran
Keywords Carbon nanotubes $\cdot \mathrm{ZnO}$ nanoparticles $\cdot \mathrm{CNT}-$ $\mathrm{ZnO}$ hybrid $\cdot$ Sol-gel $\cdot$ Concentration ratio $\cdot$ Functional group

\section{Introduction}

Because of their unique physical and chemical properties, carbon nanotubes (CNTs) are considered to be excellent candidates for many potential applications such as nanocomposite materials, nanoelectronics, catalysis and sensors [1-10]. Due to their great hardness and toughness, multiwall CNTs (MWCNTs) keep their morphology and structure even at high nanoparticle loadings [11]. It has been indicated that the CNTs' properties can be dramatically influenced by the surface modification with organic, inorganic and biological species [12-14]. Many metal oxides and sulfides such as $\mathrm{TiO}_{2}, \mathrm{Cu}_{2} \mathrm{O}, \mathrm{Al}_{2} \mathrm{O}_{3}$, $\mathrm{Co}_{3} \mathrm{O}_{4}, \mathrm{MgO}, \mathrm{Fe}_{x} \mathrm{O}_{y}, \mathrm{ZnS}$ and $\mathrm{CdS}$ have been used to modify the CNTs [12-15]. Zink oxide is a semiconductor material with an energy gap of $3.37 \mathrm{eV}$ and a large exciton binding energy $(60 \mathrm{meV})$ at room temperature [16-19]. $\mathrm{ZnO}$ has remarkable physical and chemical properties including nontoxic nature, low cost, high optical activity and stability, high sensitivity of UV-Vis light and high thermal and mechanical stability at room temperature $[12,13,16,17,20,21]$. These properties revealed that the $\mathrm{ZnO}$ is a useful material in electronics, optics, photonics, room temperature UV lasers, light emitting diodes and sensors [10-13, 20, 22]. Also it is applicable in photocatalytic degradation of organic pollutants under UV-Vis light $[9,20,23]$.

MWCNT-ZnO hybrids have unique properties different from alone CNT and $\mathrm{ZnO}[9,12]$. CNTs are good electron acceptors and $\mathrm{ZnO}$ is a good electron donor under UV illumination. MWCNTs act as photogenerated electron acceptors to promote interfacial electron transfer process from the 
attached $\mathrm{ZnO}$ to CNTs. Thus, the recombination of photo induced electron and hole would be retarded. This process enhances the photocatalytic activity of CNT-ZnO hybrid nanostructures [11]. Chen et al. synthesized $\mathrm{ZnO}$ nanoparticles decorated MWCNTs nanocomposite by a sol-gel method and observed that by increasing the calcination temperature from 450 to $700{ }^{\circ} \mathrm{C}$ the sizes of $\mathrm{ZnO}$ nanoparticles increase and the layer of coated $\mathrm{ZnO}$ becomes discontinuous [13]. Wang et al. conducted a report on covalent attachment of $\mathrm{ZnO}$ nanostructures to MWCNTs through C-N bonds. Two different morphologies of nanohybrids; flower-like $\mathrm{ZnO}$ on the tips of MWCNTs and ZnO nanoparticles on the surface of MWCNTs were obtained via adjusting the reaction time [12]. Yang et al. utilized an ex situ chemical preparation of CNT$\mathrm{ZnO}$ nanohybrids and observed that addition of a cationic surfactant (cetyltrimethylammonium bromide; $\mathrm{CTAB}$ ) prevents the agglomeration of $\mathrm{ZnO}$ nanoparticles and results in uniform distribution of $\mathrm{ZnO}$ nanoparticles decorated on CNTs' surfaces [10]. Our present work aims to grow the valuable CNT-ZnO nanostructures by a simple sol-gel method. Furthermore the effect of precursor concentration ratio and type of CNTs' functional group on synthesis of this nanostructure was investigated. Although CNT-ZnO nanohybrids were successfully synthesized by various methods, further exploration is still motivated [10-13, 15 and references there in]. The structure and morphology of CNT- $\mathrm{ZnO}$ hybrids are very sensitive to experimental parameters especially by sol-gel process $[10-13,15$ and references there in, 24]. Based on our literature review the effect of functional group of CNTs on CNT-ZnO hybrid formation was not or less investigated. In this study, we report the appearance of almost perfectly spherical $\mathrm{ZnO}$ nanoparticles attached to the surfaces of CNTs in restricted positions which was less observed. Dependence of the size, abundance, and distribution of $\mathrm{ZnO}$ particles on CNT:ZnO mass ratio was clearly evidenced.

\section{Materials and method}

In order to synthesize MWCNT-ZnO hybrid, a simple sol-gel process was applied which is similar to the route explained in Zhu et al. report [11]. Figure 1 shows the chart of the process. MWCNT with $\mathrm{COOH}$ and $\mathrm{OH}$ functional groups (denoted by MWCNT-COOH and MWCNT-OH supplied by US nano) zinc acetate $\left[\mathrm{Zn}\left(\mathrm{CH}_{3} \mathrm{COO}\right)_{2} \cdot 2 \mathrm{H}_{2} \mathrm{O}\right.$ supplied by Merck], diethylene glycol (DEG, $\mathrm{C}_{4} \mathrm{H}_{10} \mathrm{O}_{3}$ supplied by Merck), absolute ethanol (Merck) and deionized water were used as reactants. First, $0.33 \mathrm{~g}$ of $\mathrm{Zn}\left(\mathrm{CH}_{3} \mathrm{COO}\right)_{2} \cdot 2 \mathrm{H}_{2} \mathrm{O}$ was dissolved in $75 \mathrm{ml}$ DEG and then $3 \mathrm{ml}$ deionized water was added to the solution. The solution was stirred at $160-180{ }^{\circ} \mathrm{C}$ for 5 min and kept at room temperature for $2 \mathrm{~h}$ to obtain $\mathrm{ZnO}$ sol. Subsequently, certain amount of functional MWCNTs was added to the $\mathrm{ZnO}$ sol and sonicated for $30 \mathrm{~min}$ (the mass of MWCNTs were

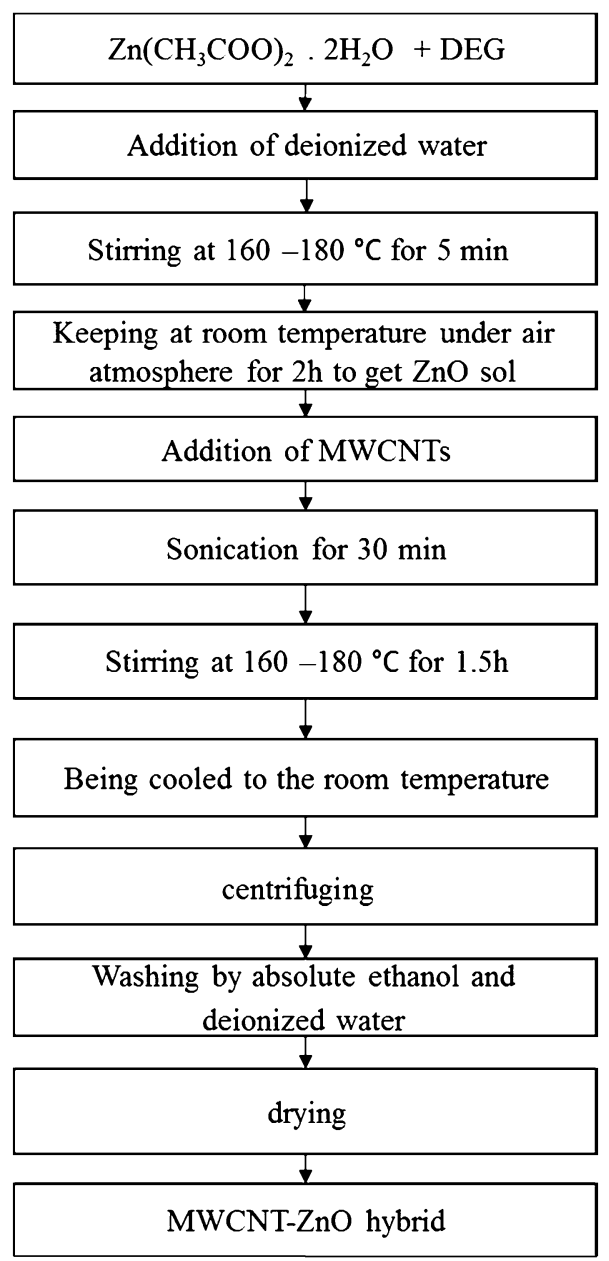

Fig. 1 Schematic diagram of sol-gel process used to synthesize CNT-ZnO hybrids

0.36, 0.12 and 0.04 to obtain the mass ratio of MWCNTs: $\mathrm{ZnO}=3: 1,1: 1,1: 3$, respectively). After that the solution was stirred at $160-180{ }^{\circ} \mathrm{C}$ for $1.5 \mathrm{~h}$ and then cooled down to the room temperature. Finally, the solution was centrifuged and washed with dionized water and absolute ethanol and dried in an oven at temperature of $60{ }^{\circ} \mathrm{C}$ for $48 \mathrm{~h}$.

The obtained powder (MWCNT-ZnO hybrid) was characterized by field emission scanning electron microscopy (FESEM, Mira 3-XMU), X-ray diffraction (XRD, PW17C PHILIPS), energy dispersive X-ray spectroscopy (EDX analyzer attached to FESEM apparatus) and Fourier transform infrared spectroscopy (FTIR, BRUKER).

\section{Results and discussion}

\section{X-ray diffraction (XRD)}

In order to determine the phase and structure of the synthesized nanohybrids XRD analysis was performed. 


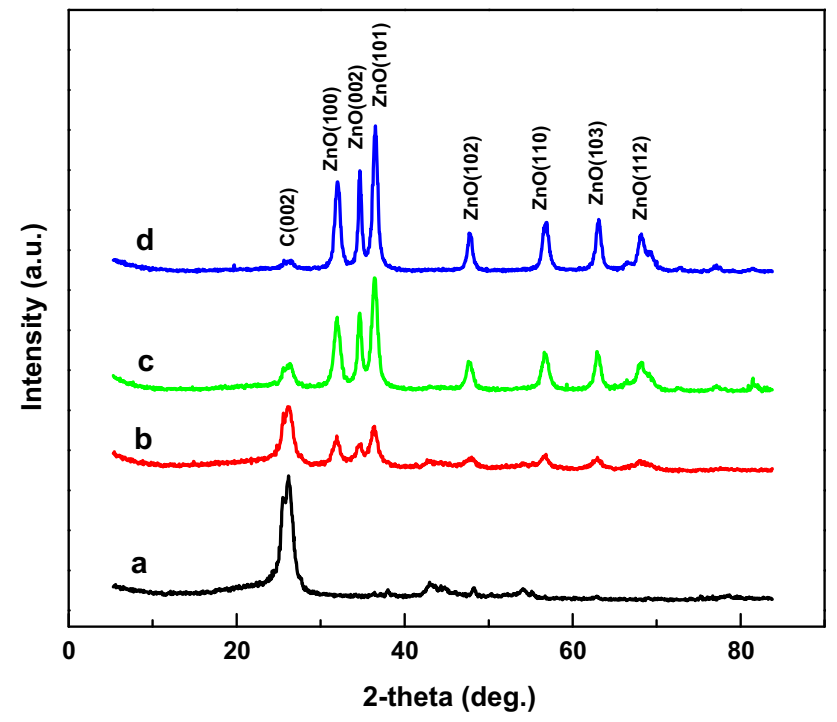

Fig. 2 XRD patterns of the a MWCNT-COOH and hybrid samples, b MWCNT-COOH-ZnO [3:1], c MWCNT-COOH-ZnO [1:1] and d MWCNT-COOH-ZnO [1:3]

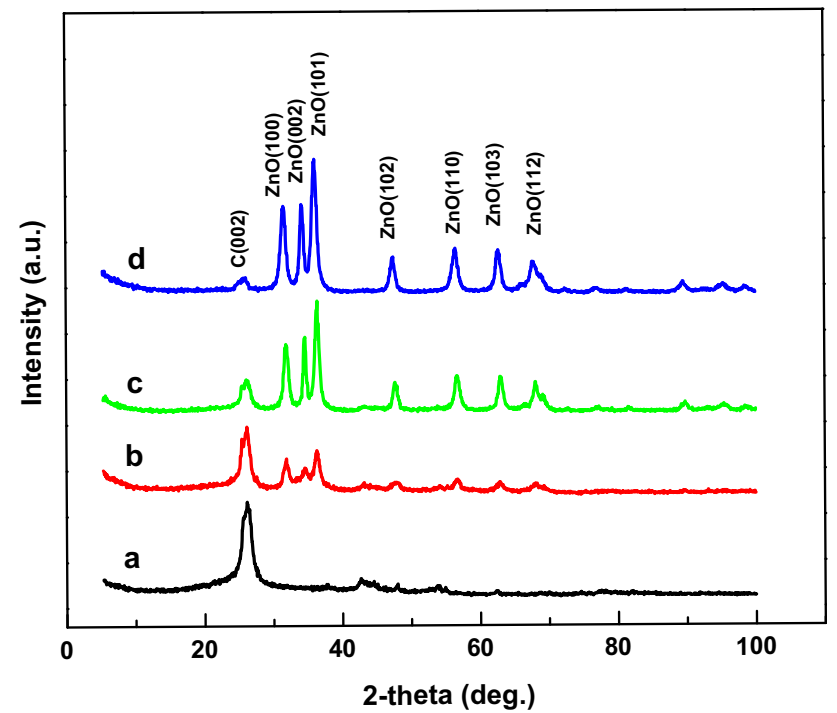

Fig. 3 XRD patterns of the a MWCNT-OH and hybrid samples, b MWCNT-OH-ZnO [3:1], c MWCNT-OH-ZnO [1:1], d MWCNT$\mathrm{OH}-\mathrm{ZnO}[1: 3]$

Figure 2 shows XRD patterns of the raw MWCNT-COOH and MWCNT-COOH-ZnO hybrid samples. The diffraction peaks at $2 \theta=31.7^{\circ}, 34.4^{\circ}, 36.2^{\circ}, 47.5^{\circ}, 56.5^{\circ}, 62.8^{\circ}$ and $67.9^{\circ}$ can be attributed to the (100), (002), (101), (102), (110), (103) and (112) crystal plates of $\mathrm{ZnO}$ with hexagonal structure, respectively $[9,11,20]$. The appearance of these peaks confirms that $\mathrm{ZnO}$ crystallites are formed in hybrid samples. The peaks at $2 \theta=26^{\circ}$ and $44^{\circ}$ are attributed to the graphite structure of MWCNTs [9, 11, 20]. Between zinc oxide's peaks, the three most intense peaks

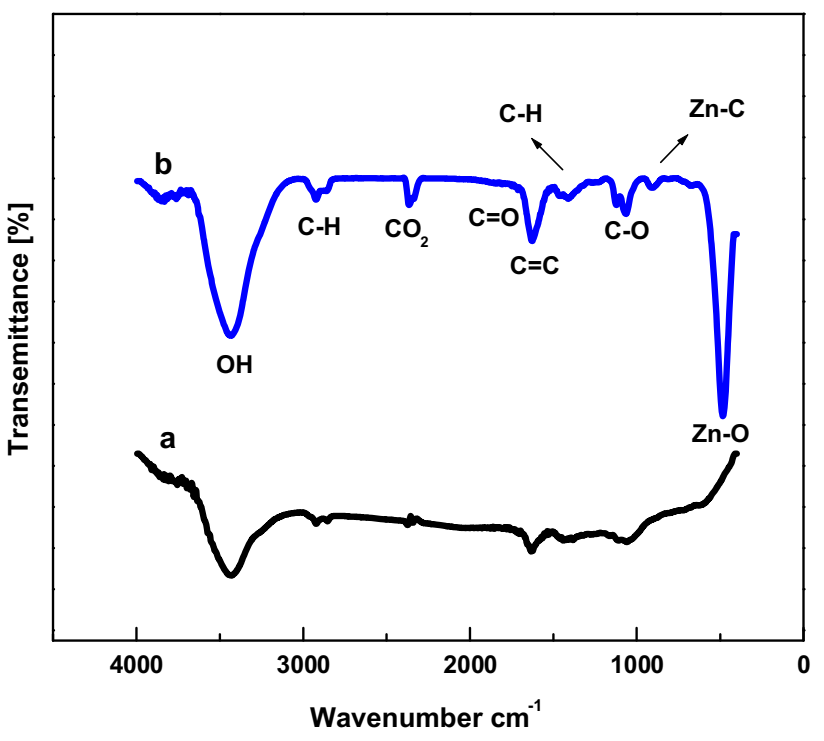

Fig. 4 FTIR spectra of the a MWCNT-COOH and b MWCNT$\mathrm{COOH}-\mathrm{ZnO}[1: 3]$

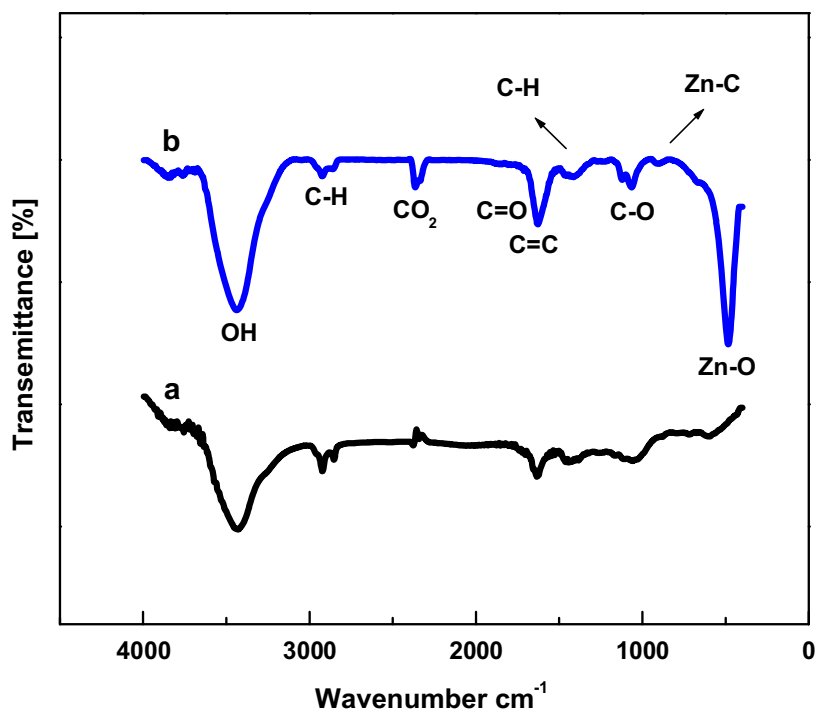

Fig. 5 FTIR spectra of the a MWCNT-OH and $\mathbf{b}$ MWCNT-OH-ZnO $[1: 3]$

are related to (100), (002) and (101) crystal plates as observed elsewhere $[13,21]$. The peak intensities of the $\mathrm{CNT}$ and $\mathrm{ZnO}$ are different in various samples depended to the concentration ratio of carbon nanotubes and zinc oxide. It can be seen that with increasing the concentration of $\mathrm{ZnO}$ precursor, the intensity of the CNTs' peaks (especially at $26^{\circ}$ ) dramatically decreases and the peaks of $\mathrm{ZnO}$ become stronger. Thus, we can conclude that with increasing the amount of $\mathrm{ZnO}$ precursor, more $\mathrm{ZnO}$ nanoparticles cover the CNTs' surfaces. Figure 3 represents the XRD patterns of the raw MWCNT-OH and MWCNT-OH-ZnO hybrid 
Fig. 6 FESEM images of the a MWCNT-COOH and hybrid samples, b MWCNT-COOH$\mathrm{ZnO}$ [3:1], c MWCNT-COOH$\mathrm{ZnO}[1: 1]$ and d MWCNT$\mathrm{COOH}-\mathrm{ZnO}[1: 3]$
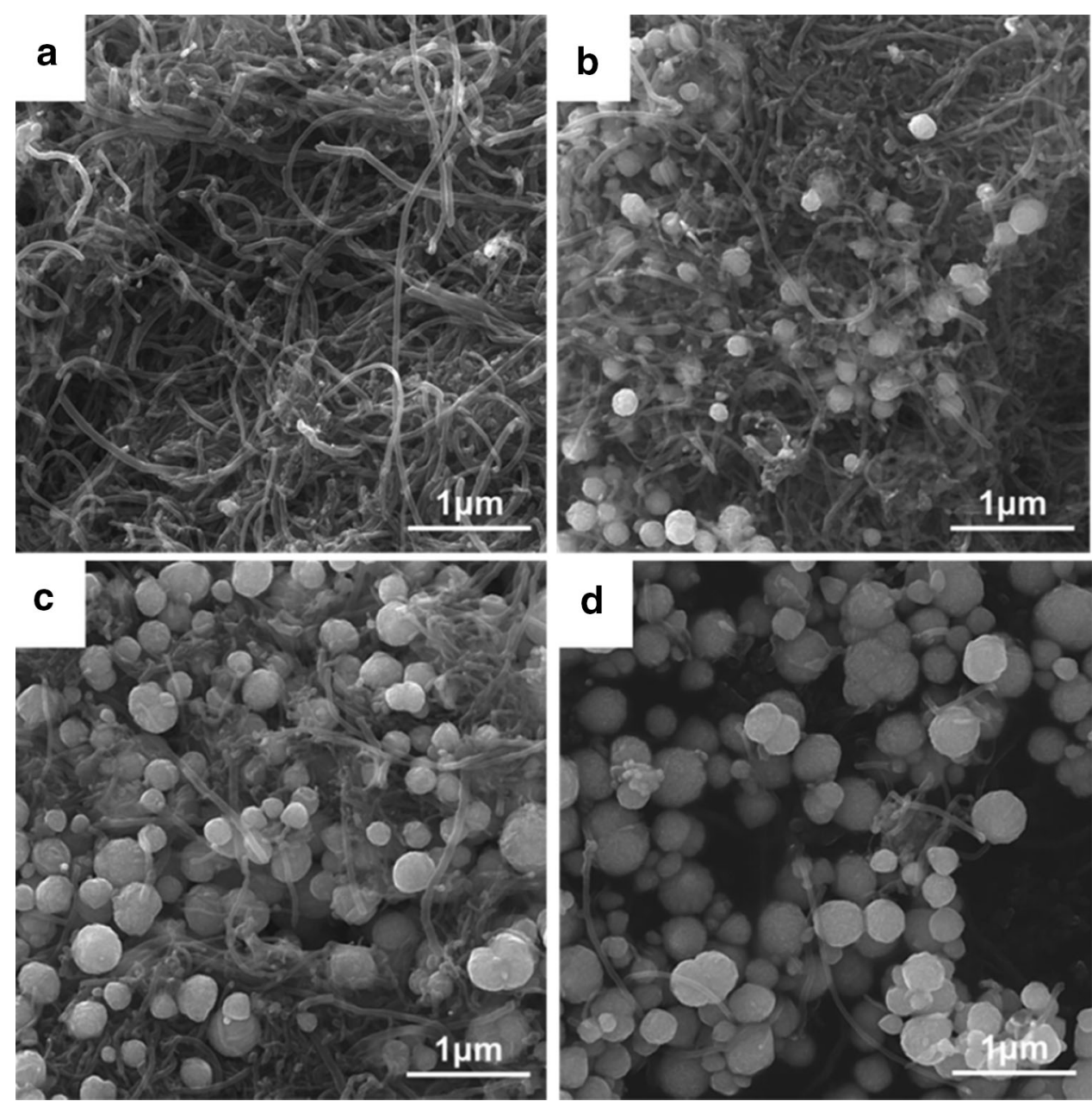

samples. Similar results were obtained for MWCNT-OH$\mathrm{ZnO}$ hybrid samples.

\section{Fourier transform infrared spectroscopy (FTIR)}

Fourier transform infrared spectroscopy was performed to understand further the formation of MWCNT-ZnO nanohybrid and the surface chemistry of prepared nanostructures. Figures 4 and 5 show the FTIR spectrum of the raw MWCNT-COOH, MWCNT-OH and typical hybrid samples with concentration ratio of MWCNT-ZnO $=1: 3$ in the range of $4000-400 \mathrm{~cm}^{-1}$ wave number. In the high frequency region, the absorption peaks at about $3440 \mathrm{~cm}^{-1}$ can be assigned to the bending vibrations of adsorbed molecular water and stretching vibrations of $\mathrm{OH}$ groups. The peaks appeared at about $2340 \mathrm{~cm}^{-1}$ correspond to the $\mathrm{CO}_{2}$ that adsorbed on the surface of the samples. $\mathrm{C}-\mathrm{H}$ groups' stretching vibration peaks are at about $2850-2900 \mathrm{~cm}^{-1}$. The absorption peaks in the range of $1630-1716 \mathrm{~cm}^{-1}$ exhibit the vibration modes of $\mathrm{COOH}$
$(\mathrm{C}=\mathrm{O}$ and $\mathrm{C}=\mathrm{C})$ functional group. In the low frequency or fingerprint region the peaks at about 484 and $910 \mathrm{~cm}^{-1}$ (which are appeared in hybrid samples and are absent in the raw functional CNT spectrums) are related to the $\mathrm{Zn}-\mathrm{O}$ and $\mathrm{Zn}-\mathrm{C}$ bonds on the surface of the CNTs. These peaks support the fact that $\mathrm{ZnO}$ nanoparticles are synthesized and attached to the surfaces of CNTs $[9,11,25]$.

\section{Scanning electron microscopy (SEM)}

Figure 6 shows the FESEM images of the initial MWCNT$\mathrm{COOH}$ and MWCNT-COOH-ZnO hybrid nanomaterials. Figure $6 \mathrm{a}$ shows the filamentous and smooth morphology of initial carboxyl MWCNTs. For hybrid samples (Fig. 6b, c, d) sphere-like nanoparticles on the matrix of CNTs are appeared. Further characterization revealed that these rather spherical particles are $\mathrm{ZnO}$ nanoparticles. Thus, the simple sol-gel process resulted in successful growth of CNT-ZnO hybrids. Furthermore, it can be seen that with increasing the concentration ratio of $\mathrm{ZnO}$ precursor to 

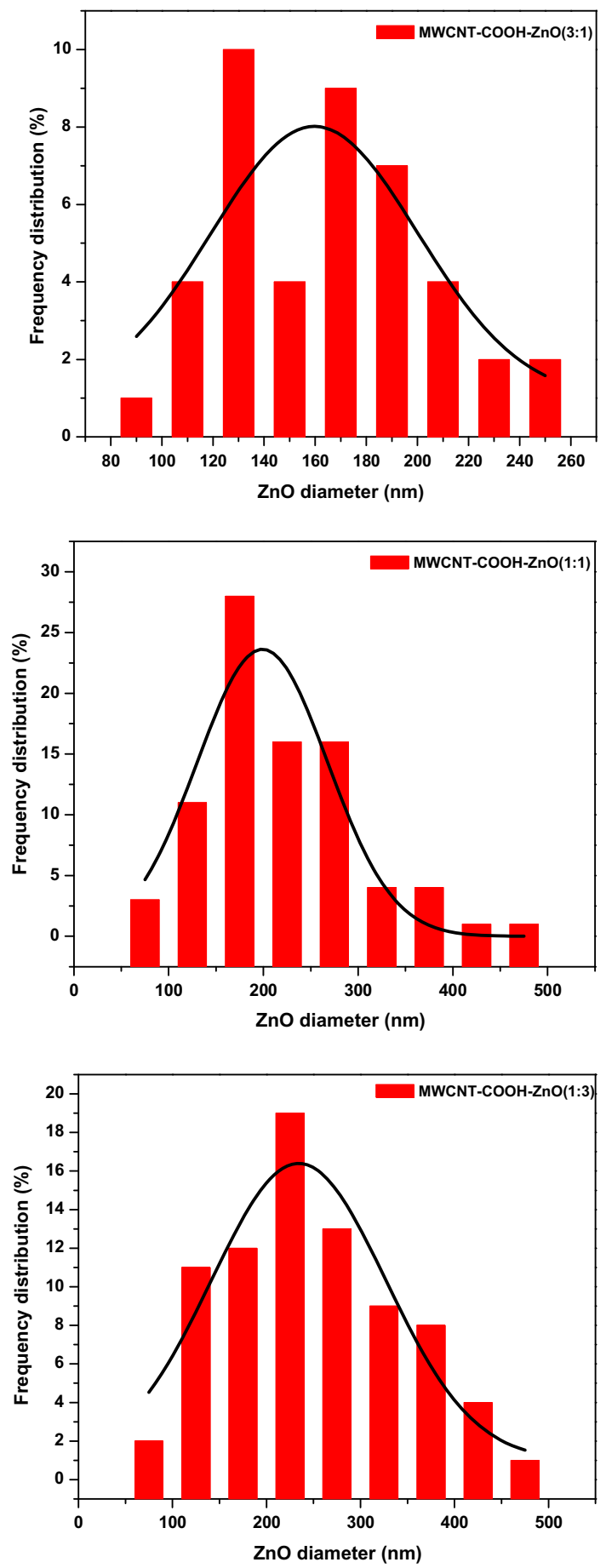

Fig. 7 Size distribution histograms of $\mathrm{ZnO}$ nanoparticles synthesized in MWCNT-COOH-ZnO hybrids

$\mathrm{CNT}$, the number and sizes of attached $\mathrm{ZnO}$ nanoparticles on the surface of the MWCNTs are increased. Figure 7 represents the size distribution histograms (derived from SEM images) of $\mathrm{ZnO}$ nanoparticles synthesized in MWCNT-COOH-ZnO hybrid nanostructures. Each histogram is fitted by a normal curve. According to these histograms the average diameter of $\mathrm{ZnO}$ nanoparticles in MWCNT-COOH-ZnO hybrid samples with concentration ratio of MWCNT:ZnO = 3:1, 1:1 and 1:3 are 160, 220 and $250 \mathrm{~nm}$, respectively. Figure 8 shows the FESEM images of the initial MWCNT-OH and MWCNT-OH-ZnO hybrid nanomaterials. Similar hybrid morphologies appeared in these samples. Similarly by increasing the concentration of $\mathrm{ZnO}$ precursor in nanohybrid preparation, the size and number of $\mathrm{ZnO}$ nanoparticles are increased. Histograms of size distribution of $\mathrm{ZnO}$ nanoparticles for MWCNT-OH$\mathrm{ZnO}$ nanohybrids are represented in Fig. 9. According to this figure the average diameter of $\mathrm{ZnO}$ nanoparticles in MWCNT-OH-ZnO hybrid samples with concentration ratio of MWCNT:ZnO = 3:1, 1:1 and 1:3 are 165, 250 and $260 \mathrm{~nm}$,respectively. Therefore, at the same concentration ratio of $\mathrm{ZnO}$ precursor to $\mathrm{CNT}$, relatively smaller $\mathrm{ZnO}$ nanoparticles on $\mathrm{COOH}$ functionalized CNTs are synthesized compared to $\mathrm{OH}$ functionalized ones. Furthermore it seems (compare Fig. 6 with Fig. 8) that the distribution of $\mathrm{ZnO}$ nanoparticles in MWCNT-COOH-ZnO hybrids is more uniform and denser compared to MWCNT-OH-ZnO samples.

\section{Energy dispersive X-ray spectroscopy (EDX)}

For further comparison between $\mathrm{COOH}$ and $\mathrm{OH}$ functionalized CNT-ZnO hybrids, EDX analysis was performed. Figure 10 shows the EDX spectrum of MWCNT-COOH$\mathrm{ZnO}$ hybrid samples. As we expected it confirms the presence of $\mathrm{C}, \mathrm{O}$ and $\mathrm{Zn}$ elements in the hybrid samples. Quantitative results obtained from EDX analysis revealed that the wt $\%$ of $\mathrm{Zn}$ deposited on the surface of MWCNT$\mathrm{COOH}$ was $12.5,36.4$ and 64.9 for MWCNT:ZnO mass ratio $=3: 1,1: 1$ and 1:3, respectively. Thus, as we expected the amount of $\mathrm{ZnO}$ nanoparticles loaded on the surface of CNTs increases by MWCNT:ZnO ratio as the following trend $3: 1<1: 1<1: 3$. Similar result for MWCNT-OH$\mathrm{ZnO}$ was obtained. The EDX analysis of MWCNT-OH$\mathrm{ZnO}$ revealed that the wt $\%$ of $\mathrm{Zn}$ deposited on the surface of MWCNT-OH was 10.8, 32.0 and 53.4. The amount of $\mathrm{ZnO}$ nanoparticles loaded on the surface of CNTs increases by MWCNT:ZnO ratio as similar trend 3:1<1:1<1:3. Moreover in comparison between the two functional groups, the amount of $\mathrm{ZnO}$ material loaded on the surface of CNTs with $\mathrm{COOH}$ functional group is relatively more than that of $\mathrm{OH}$ functionalized CNTs.

\section{Transmission electron microscopy (TEM)}

Figure 11 shows the TEM images of MWCNT-COOH$\mathrm{ZnO}$ hybrid samples. The dark rather spherical morphologies exhibit $\mathrm{ZnO}$ nanospheres. As indicated by these 
Fig. 8 FESEM images of the a MWCNT-OH and hybrid samples, b MWCNT-OH-ZnO [3:1], c MWCNT-OH-ZnO [1:1], d MWCNT-OH-ZnO [1:3]
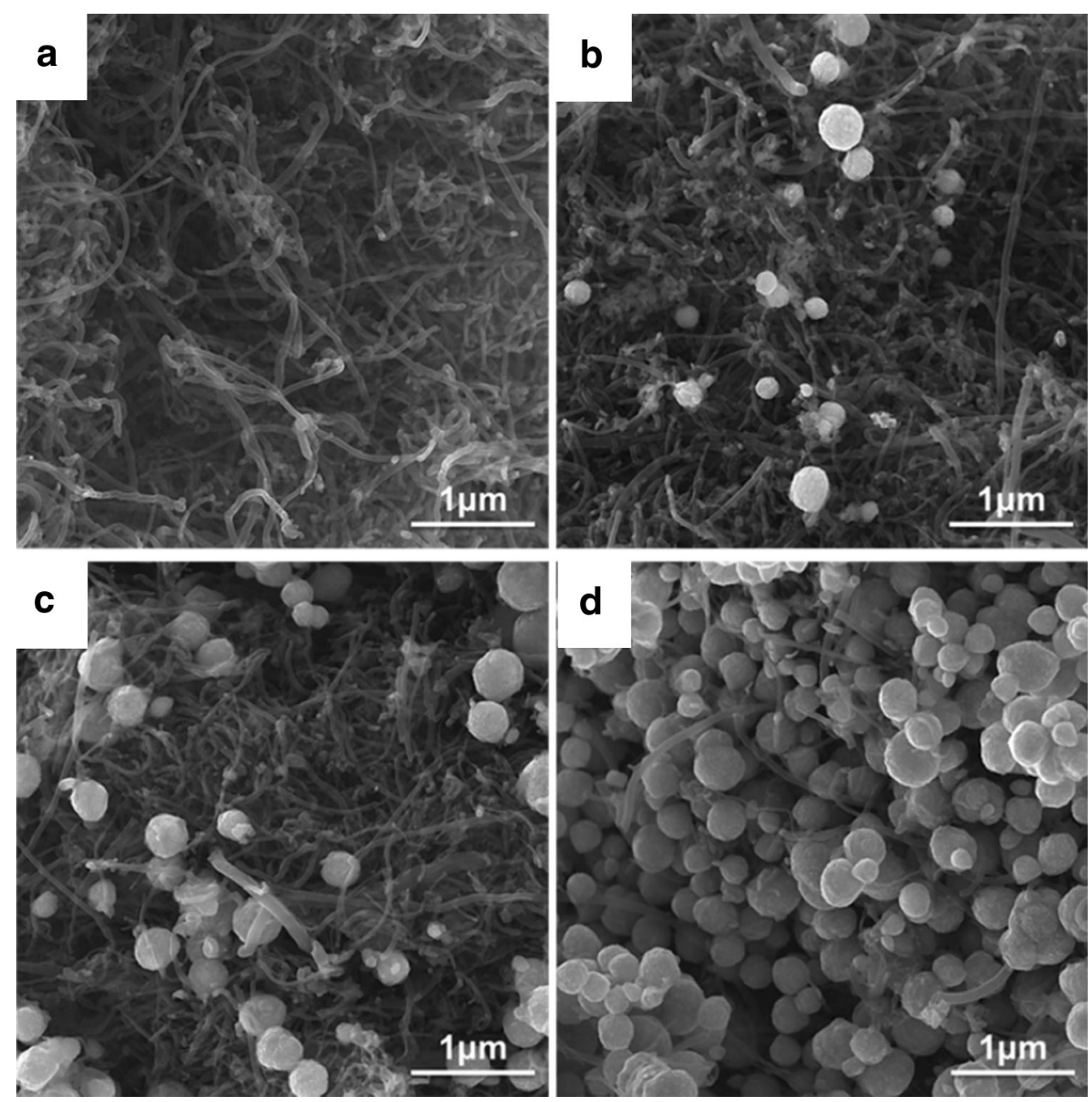

images, the spherical $\mathrm{ZnO}$ nanoparticles are attached on the tips or side-walls of CNTs. Unattached separated or isolated $\mathrm{ZnO}$ nanospheres were not observed. This observation provides a direct and strong evidence of successful formation of MWCNT-ZnO nanohybrid. By increasing the mass ratio of $\mathrm{ZnO}$ precursor to CNTs more and larger $\mathrm{ZnO}$ nanoprticles appeared.

In this study the process used to prepare zinc oxide nanoparticles and subsequent hybrid materials is a polyol process [24, 26-29]. The polyol synthesis designates the liquid-phase synthesis in high-boiling, multivalent alcohols and is mainly directed to nanoparticles. Chemically, the polyol family starts with ethylene glycol (EG) as its simplest representative. Based on EG, the polyols comprise two main series of molecules: (1) diethylene glycol (DEG), triethylene glycol (TrEG), tetraethylene glycol (TEG), and so on up to polyethylene glycol (PEG), with the latter containing more than 2000 ethylene groups, (2) propanediol (PDO), butanediol (BD), pentanediol (PD), and so on. Moreover, glycerol (GLY), pentaerythritol (PE), and carbohydrates chemically belong to the polyols $[24,26]$. In a typical polyol process, the solid precursor is suspended in the liquid polyol, and then the solution or the suspension is stirred and heated to a given temperature which can reach the boiling point of the polyol. Polyol is an excellent capping reagent as well as a good dispersive medium, which plays a critical role in the nucleation and growth of the crystalline nanoparticles. For the polyol-mediated synthesis of metal oxides a defined amount of water has to be added into the polyol and the relative concentration of water versus the metal concentration, i.e., the hydrolysis ratio, is a critical parameter to tune the size of the nanoparticles obtained through spontaneous nucleation [26]. The growth mechanism of $\mathrm{ZnO}$ coating on the surface of MWCNTs is purposed as follow [27].

The pyrolysis temperature of zinc acetate is about $350{ }^{\circ} \mathrm{C}$, while the maximum reaction temperature of this study is $180{ }^{\circ} \mathrm{C}$. Thus, the formation of $\mathrm{ZnO}$ sol is not through pyrolysis but rather hydrolysis process according to the Eq. (1):

$\mathrm{Zn}\left(\mathrm{CH}_{3} \mathrm{COO}\right)_{2}+\mathrm{H}_{2} \mathrm{O} \Rightarrow \mathrm{ZnO}+2 \mathrm{CH}_{3} \mathrm{COOH}$.

After the hydrolysis of zinc acetate, $\mathrm{ZnO}$ crystal nuclei are first formed directly, followed by growing up gradually. 

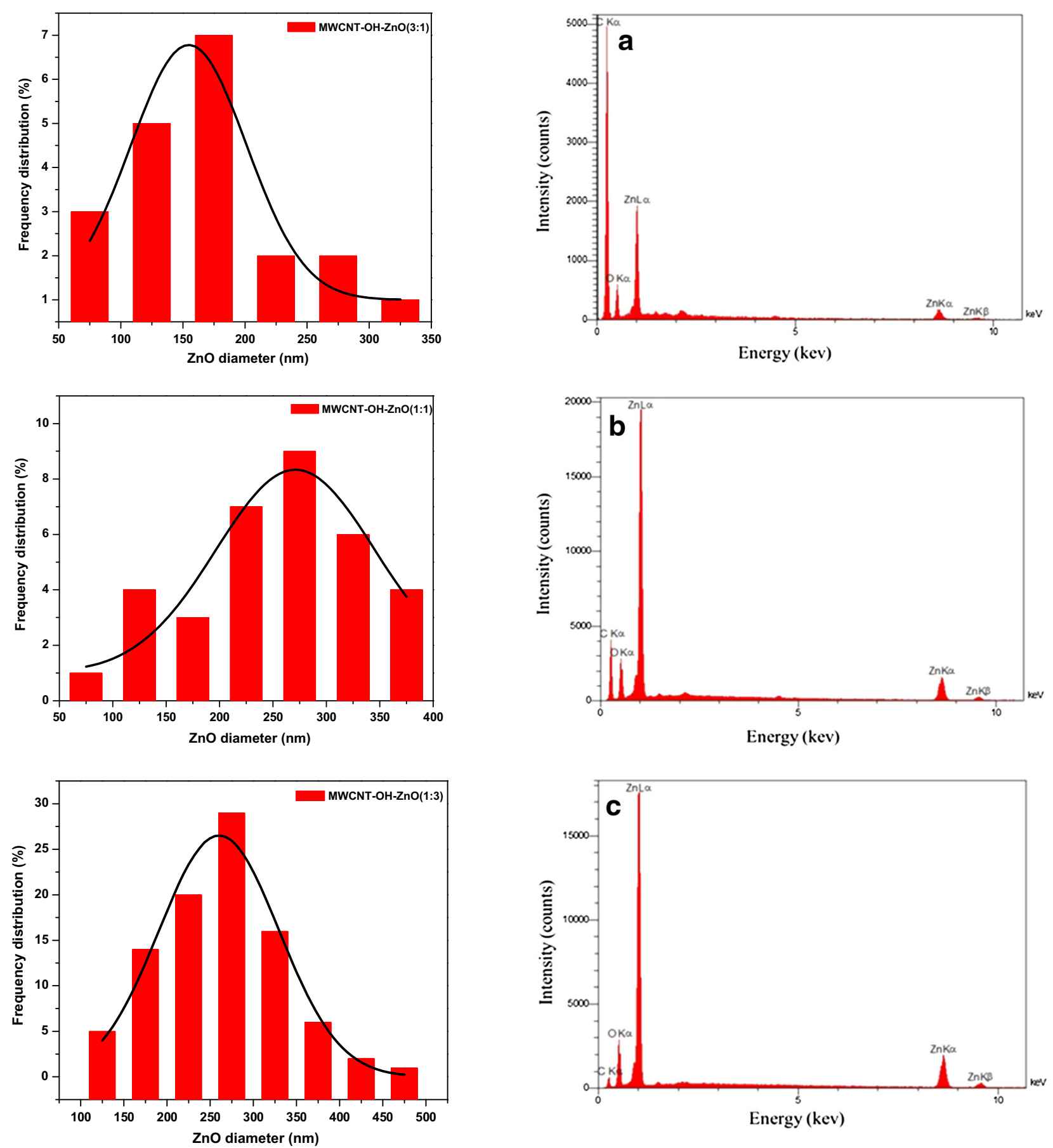

Fig. 9 Size distribution histograms of $\mathrm{ZnO}$ nanoparticles synthesized in MWCNT-OH-ZnO hybrids

Fig. 10 EDX analysis of hybrid samples: a MWCNT-COOH-ZnO [3:1], b MWCNT-COOH-ZnO [1:1] and c MWCNT-COOH-ZnO $[1: 3]$

Since DEG in the system can react with acetic acid, it speeds up the reaction in Eq. (1). Moreover, the presence of DEG is used as a solvent to raise the viscosity of the solution, which causes the crystallization rate to slow down. Therefore, the system has enough time to form many crystal nuclei and to grow $\mathrm{ZnO}$ crystals at high temperatures.

On the other hand, electrical double layers composed of $\mathrm{Zn}^{2+}$ on the surface of $\mathrm{ZnO}$ sol particles and acetate anions surrounded these particles [27] provide positive charges and repulsive interactions which stabilize the colloidal sol. Because of the presence of hydroxyl and carboxyl functional groups, the MWCNTs become negatively charged; 
Fig. 11 TEM images of the hybrid samples: a MWCNT$\mathrm{COOH}-\mathrm{ZnO}$ [3:1], b MWCNT$\mathrm{COOH}-\mathrm{ZnO}[1: 1]$ and c MWCNT-COOH-ZnO [1:3]
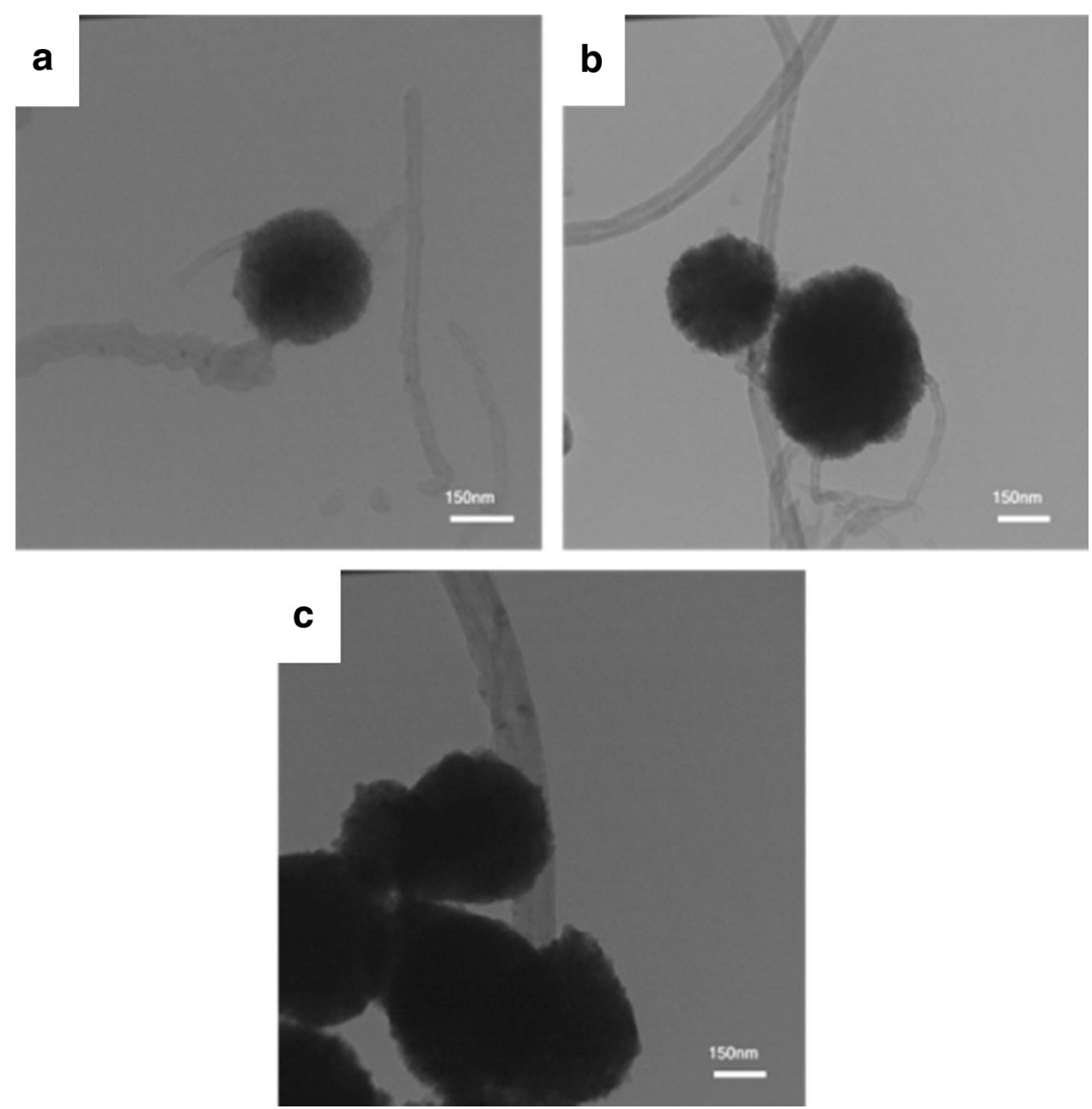

so the $\mathrm{ZnO}$ nanoparticles attach to the MWCNT surfaces by electrostatic attractions [28, 29].

\section{Conclusions}

A simple sol-gel method was used to synthesis the MWCNT-ZnO hybrid nanosrtuctures. Two type of functional MWCNT with $\mathrm{COOH}$ and $\mathrm{OH}$ functional groups and three concentration ratio of MWCNT: $\mathrm{ZnO}=3: 1,1: 1$ and 1:3 were examined. The appearance of $\mathrm{Zn}-\mathrm{O}$ and $\mathrm{Zn}-\mathrm{C}$ vibration modes in FTIR spectrum of hybrid samples revealed the formation of $\mathrm{ZnO}$ nanoparticles and attachment of these particles to the surfaces of CNTs. The XRD patterns of hybrid samples support the fact that the $\mathrm{ZnO}$ nanoparticles with hexagonal crystal structure decorated the body of CNTs. The SEM observation showed that the $\mathrm{ZnO}$ nanoparticles have rather spherical shapes. It was observed that with increasing the concentration of $\mathrm{ZnO}$ precursor, the size and number of $\mathrm{ZnO}$ nanoparticles which cover the surfaces of CNTs (for both functional groups) were increased. The average diameter of $\mathrm{ZnO}$ nanoparticles in MWCNT-
$\mathrm{COOH}-\mathrm{ZnO}$ (MWCNT-OH-ZnO) hybrid samples with concentration ratio of MWCNT:ZnO = 3:1, 1:1 and 1:3 are 160(165), 220(250) and 250(260) nm, respectively. The average sizes of $\mathrm{ZnO}$ nanoparticles decorated the MWCNT$\mathrm{COOH}$ are smaller than that of MWCNT-OH and the amount of $\mathrm{ZnO}$ material loaded on the surface of MWCNT-COOH is more than that of MWCNT-OH.

Open Access This article is distributed under the terms of the Creative Commons Attribution 4.0 International License (http://crea tivecommons.org/licenses/by/4.0/), which permits unrestricted use, distribution, and reproduction in any medium, provided you give appropriate credit to the original author(s) and the source, provide a link to the Creative Commons license, and indicate if changes were made.

\section{References}

1. De Volder, M.F.L., Tawfick, S.H., Baughman, R.H., Hart, A.J.: Carbon nanotubes: present and future commercial applications. Science 339, 535-539 (2013)

2. Tan, C.W., Tan, K.H., Ong, Y.T., Mohamed, A.R., Zein, S.H.S., Tan, S.H.: Energy and environmental applications of carbon nanotubes. Environ. Chem. Lett. 10, 265-273 (2012) 
3. Verma, P., Saini, P., Malik, R.S., Choudhary, V.: Excellent electromagnetic interference shielding and mechanical properties of high loading carbon-nanotubes/polymer composites designed using melt recirculation equipped twin-screw extruder. Carbon 89, 308-317 (2015)

4. Cheng, Y., Xu, C., Jia, L., Gale, J.D., Zhang, L., Liu, C., Shen, P.K., Jiang, S.P.: Pristine carbon nanotubes as non-metal electrocatalysts for oxygen evolution reaction of water splitting. Appl. Catal. B. 163, 96-104 (2015)

5. Ghodselahi, T., Solaymani, S., Akbarzadeh Pasha, M., Vesaghi, M.A.: Ni nanoparticle catalyzed growth of MWCNTs on $\mathrm{Cu}$ NPs@ aC: H substrate. Eur. Phys. J. D 66, 299-303 (2012)

6. Chen, C.S., Liu, T.G., Lin, L.W., Xie, X.D., Chen, X.H., Liu, Q.C., Liang, B., Yu, W.W., Qiu, C.Y.: Multi-walled carbon nanotube-supported metal-doped $\mathrm{ZnO}$ nanoparticles and their photocatalytic property. J. Nanopart. Res. 15, 1295-1304 (2013)

7. Wang, X., Yao, S., Li, X.: Sol-gel preparation of CNT/ZnO nanocomposite and its photocatalytic property. Chin. J. Chem. 27, 1317-1320 (2009)

8. Zhang, W.D., Xu, B., Jiang, L.C.: Functional hybrid materials based on carbon nanotubes and metal oxides. J. Mater. Chem. 20, 6383-6391 (2010)

9. Samadi, M., Shivaee, H.A., Zanetti, M., Pourjavadi, A., Moshfegh, A.: Visible light photocatalytic activity of novel MWCNTdoped $\mathrm{ZnO}$ electrospun nanofibers. J. Mol. Catal. A Chem. 359, 42-48 (2012)

10. Yang, M., Liang, T., Peng, Y., Chen, Q.: Synthesis and characterization of a nanocomplex of $\mathrm{ZnO}$ nanoparticles attached to carbon nanotubes. Acta Phys. Chim. Sin. 23, 145-151 (2007)

11. Zhu, L.P., Liao, G.H., Huang, W.Y., Ma, L.L., Yang, Y., Yu, Y., Fu, S.Y.: Preparation, characterization and photocatalytic properties of ZnO-coated multi-walled carbon nanotubes. Mater. Sci. Eng. B. 163, 194-198 (2009)

12. Wang, X., Xia, B., Zhu, X., Chen, J., Qiu, S., Li, J.: Controlled modification of multiwalled carbon nanotubes with Zno nanostructures. J. Solid State Chem. 181, 822-827 (2008)

13. Chen, C.S., Chen, X.H., Yi, B., Liu, T.G., Li, W.H., Xu, L.S., Yang, Z., Zhang, H., Wang, Y.G.: Zinc oxide nanoparticle decorated multi-walled carbon nanotubes and their optical properties. Acta Mater. 54, 5401-5407 (2006)

14. Dalouji, V., Elahi, S.M., Solaymani, S., Ghaderi, A.: Absorption edge and the refractive index dispersion of carbon-nickel composite films at different annealing temperatures. Eur. Phys. J. Plus 131, 1-6 (2016)

15. Eder, D.: Carbon nanotube-inorganic hybrids. Chem. Rev. 110, 1348-1385 (2010)

16. Kołodziejczak-Radzimska, A., Markiewicz, E., Jesionowski, T.: Structural characterization of $\mathrm{ZnO}$ particles obtained by the emulsion precipitation method. J. Nanomater. 15, 1-9 (2012)
17. Ramar, A., Soundappan, T., Chen, S.M., Rajkumar, M., Ramiah, S.: Incorporation of multi-walled carbon nanotubes in $\mathrm{ZnO}$ for dye sensitized solar cells. Int. J. Electrochem. Sci. 7, 11734-11744 (2012)

18. Lv, T., Pan, L., Liu, X., Sun, Z.: Enhanced photocatalytic degradation of methylene blue by $\mathrm{ZnO}$-reduced graphene oxidecarbon nanotube composites synthesized via microwave-assisted reaction. Catal. Sci. Technol. 2, 2297-2301 (2012)

19. Ţălu, Ş., Bramowicz, M., Kulesza, S., Solaymani, S., Ghaderi, A., Dejam, L., Elahi, S.M., Boochani, A.: Microstructure and micromorphology of $\mathrm{ZnO}$ thin films: case study on $\mathrm{Al}$ doping and annealing effects. Superlattices Microstruct. 93, 109-121 (2016)

20. Akhavan, O., Azimirad, R., Safa, S.: Functionalized carbon nanotubes in $\mathrm{ZnO}$ thin films for photoinactivation of bacteria. Mater. Chem. Phys. 130, 598-602 (2011)

21. Jiang, L., Gao, L.: Fabrication and characterization of $\mathrm{ZnO}$ coated multi-walled carbon nanotubes with enhanced photocatalytic activity. Mater. Chem. Phys. 91, 313-316 (2005)

22. Tang, Z.K., Wong, G.K., Yu, P., Kawasaki, M., Ohtomo, A., Koinuma, H., Segawa, Y.: Room-temperature ultraviolet laser emission from self-assembled $\mathrm{ZnO}$ microcrystallite thin films. Appl. Phys. Lett. 72, 3270-3272 (1998)

23. Ahmad, M., Ahmed, E., Hong, Z.L., Ahmed, W., Elhissi, A., Khalid, N.R.: Photocatalytic, sonocatalytic and sonophotocatalytic degradation of Rhodamine $\mathrm{B}$ using $\mathrm{ZnO} / \mathrm{CNT}$ s composites photocatalysts. Ultrason. Sonochem. 21, 761-773 (2014)

24. Dong, H., Chen, Y.C., Feldman, C.: Polyol synthesis of nanoparticles: status and options regarding metals, oxides, chalcogenides, and non-metal elements. Green Chem. 17, 4107-4132 (2015)

25. Saleh, T.A., Gondal, M.A., Drmosh, Q.A., Yamani, Z.H., AlYamani, A.: Enhancement in photocatalytic activity for acetaldehyde removal by embedding $\mathrm{ZnO}$ nano particles on multiwall carbon nanotubes. Chem. Eng. J. 166, 407-412 (2011)

26. Fievet, F., Brayner, R.: The polyol process. In: Brayner, R., Fievet, F., Coradin, T. (eds.) Nanomaterials: a danger or a promise?, pp. 1-25. Springer, London (2013)

27. Yu, Y., Huang, W.Y., Li, J.L., Ma, L.L.: Preparation and photocatalytic property of $\mathrm{ZnO} / \mathrm{MWCNTs}$ composites. In: Buckley, R.W. (ed.) Solid state chemistry research trends, pp. 1-22. Nova Science Publishers, Inc., New York (2007)

28. Yu, Y., Ma, L.L., Huang, W.Y., Li, J.L., Wong, P.K., Yu, J.C.: Coating MWNTs with $\mathrm{Cu}_{2} \mathrm{O}$ of different morphology by a polyol process. J. Solid State Chem. 178, 1488-1494 (2005)

29. Jia, B., Gao, L., Sun, J.: Self-assembly of magnetite beads along multiwalled carbon nanotubes via a simple hydrothermal process. Carbon 45, 1476-1481 (2007) 